\title{
Ação antimicrobiana do gás ozônio em superficies e na aeromicrobiota
}

Antimicrobial action of ozone gas on surfaces and in the air Acción antimicrobiana del gas ozono en superficies y en la microbiota del aire

Maicon Henrique Caetano ${ }^{1}$ io https://orcid.org/0000-0002-5540-4550

João Paulo Zen Siqueira ${ }^{2}$ io https:/orcid.org/0000-0002-5807-9204

Denise de Andrade ${ }^{3}$ io https://orcid.org/0000-0002-3336-2695

Álvaro Francisco Lopes de Sousa ${ }^{3,4}$ ib https://orcid.org/0000-0003-2710-2122

Marcelo Alessandro Rigotti ${ }^{5}$ id https://orid. org/0000-0002-9234-6257

Maiara Oliveira Diniz io hitps://orcid.org/0000-0002-8823-5626

Willian Albuquerque de Almeida ${ }^{6}$ io https://orcid.org/0000-0001-7074-1988

Adriano Menis Ferreira ${ }^{5}$ io https://orcid.org/0000-0002-4054-768X

Margarete Teresa Gottardo de Almeida ${ }^{2}$ io https://orcid.org/0000-0002-8665-9126

Como citar:

Caetano MH, Siqueira JP, Andrade D, Sousa AF, Rigotti MA, Diniz MO, et al. Ação antimicrobiana do gás ozônio em superfícies e na aeromicrobiota. Acta Paul Enferm. 2021;34:APE02712.

DOI

http://dx.doi.org/10.37689/actaape/2021A002712

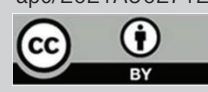

Descritores

Anti-infecciosos; Ozônio; Ozonização; Desinfecção; Produtos com ação antimicrobiana; Poluição do ar

em ambientes fechados

Keywords

Anti-infective agents; Ozone; Ozonation; Disinfection; Products with antimicrobial action; Air pollution, indoor

Descriptores Antiinfecciosos; Ozono; Ozonización; Desinfección; Productos con acción antimicrobiana; Contaminación del aire interior

Submetido 17 de Setembro de 2019 Aceito 20 de Agosto de 2020

Autor correspondente Margarete Teresa Gottardo de Almeida E-mail: margarete@famerp.br

\section{Resumo}

Objetivo: Avaliar a ação antimicrobiano do gás ozônio $\left(\mathrm{O}_{3}\right)$ em superfícies e ar ambiente climatizado artificialmente.

Métodos: Estudo experimental/laboratorial e transversal realizado em dez salas de um laboratório de pesquisa em microbiologia médica, com risco de segurança biológica classe 2. As superfícies demarcadas do chão, parede e bancada foram avaliadas, quanto à presença ou ausência de micro-organismos, a partir de coletas feitas com swab umedecido em água destilada estéril, antes e após a exposição do gás $0_{3}$ gerado por dois equipamentos distintos. Após este procedimento, o swab foi inoculado na superfície do meio de cultura Brain Heart Infusion AgarDIFCO ${ }^{\circledR}(\mathrm{BHI})$, seguindo-se a incubação a $35^{\circ} \mathrm{C}$ por 24 horas. Para a análise microbiológica do ar, uma placa com BHI foi exposta aberta por uma hora, antes e após o tratamento do gás $0_{3}$ sendo incubadas segundo os mesmos critérios.

Resultados: $A$ atividade antimicrobiana do gás $\mathrm{O}_{3}$ gerado por ambos os equipamentos foi constatada para todas as áreas investigadas, com registros de redução do número de Unidades Formadoras de Colônias. 0 potencial de inibição antimicrobiana dos aparelhos se manteve próximo para os critérios de análise adotados, com destaque para as áreas de chão e bancada. Considerando-se todas as salas e percentuais de inibição microbiana, frente aos dois equipamentos, os resultados foram: chão (100\%), bancada (90\%), parede (50\%) e ar, $70 \%$.

Conclusão: Os equipamentos geradores de gás $\mathrm{O}_{3}$ apresentaram potencial antimicrobiano para medida de controle de microrganismos presentes em superfícies e ar ambiente climatizado artificialmente, sendo um sanitizante factível para utilização.

\section{Abstract}

Objective: Assess the antimicrobial action of ozone gas $\left(\mathrm{O}_{3}\right)$ on surfaces and artificially cooled ambient air.

Methods: Cross-sectional experimental/laboratory study carried out in ten rooms of a medical microbiology research lab, with class 2 biosafety risk. The demarcated surfaces on the floor, wall and counter were assessed in relation to the presence or absence of microorganisms, based on collections done with swabs dampened in sterile distilled water, before and after exposure to ozone gas produced by two different generators. After this procedure, each swab was inoculated on the surface of a Brain Heart Infusion Agar DIFCO ${ }^{\circledR}(\mathrm{BHI})$ culture, followed by incubation at $35^{\circ} \mathrm{C}$ for 24 hours. For the microbiological analysis of the air, a petri dish with $\mathrm{BH}$ was openly exposed for one hour, before and after treatment with $\mathrm{O}_{3}$ gas, and were incubated according to the same criteria. 
Results: The antimicrobial activity of the $\mathrm{O}_{3}$ gas produced by both generators was checked in all the areas investigated, with records indicating a decrease in the number of colony-forming units. The antimicrobial inhibition potential of the generators was close to the analysis criteria adopted, particularly for the floor and counter areas. Based on all the rooms and microbial inhibition percentages, in relation to the two generators, the results were: floor (100\%), counter (90\%), wall (50\%) and air (70\%).

Conclusion: The $\mathrm{O}_{3}$ generators had antimicrobial potential as a procedure for controlling microorganisms present on surfaces and in artificially cooled ambient air, constituting a feasible sanitizer.

\section{Resumen}

Objetivo: Evaluar la acción antimicrobiana del gas ozono $\left(\mathrm{O}_{3}\right)$ en superficies y en el aire interior climatizado artificialmente.

Métodos: Estudio experimental/de laboratorio y transversal realizado en diez salas de un laboratorio de investigación en microbiología médica, con riesgo de seguridad biológica clase 2. Se evaluaron las superficies delimitadas en el piso, pared y mesa en cuanto a la presencia 0 ausencia de microorganismos, a partir de muestras recolectadas con hisopo humedecido en agua destilada estéril, antes y después de la exposición del gas $0_{3}$ generado por dos máquinas distintas. Luego de este procedimiento, el hisopo fue inoculado en la superficie del medio de cultivo Brain Heart Infusion Agar DIFCO ${ }^{\circledR}$ (BHI), y después incubado a $35^{\circ} \mathrm{C}$ por 24 horas. Para el análisis microbiológico del aire, se expuso una placa con $\mathrm{BH}$ abierta durante una hora, antes y después del tratamiento del gas $\mathrm{O}_{3}$, y luego se incubó con los mismos criterios.

Resultados: Se constató la actividad antimicrobiana del gas $\mathrm{O}_{3}$ generado por ambas máquinas en todas las áreas investigadas, y se registró una reducción del número de unidades formadoras de colonias. El potencial de inhibición antimicrobiana de los dispositivos se mantuvo próximo a los criterios de análisis adoptados, con énfasis en el área del piso y mesa. Considerando todas las salas y porcentajes de inhibición microbiana, con las dos máquinas, los resultados fueron: piso (100\%), mesa (90\%), pared (50\%) y aire (70 \%).

Conclusión: Las máquinas generadoras de gas $\mathrm{O}_{3}$ presentaron potencial antimicrobiano como medida de control de microorganismos presentes en superficies y aire interior climatizado artificialmente, lo que lo convierte en un desinfectante factible para ser usado.

\section{Introdução}

O controle de Infecçôes Relacionadas à Assistência à Saúde (IRAS) representa um assunto sensível para a saúde pública, por ser motivo de morbidade, mortalidade e custos elevados, sobretudo em países em desenvolvimento. ${ }^{(1-3)}$

$\mathrm{O}$ ambiente participa efetivamente na transmissão de micro-organismos, onde a contaminação de superfícies inanimadas é o potencial reservatório. Os equipamentos e as superfícies de áreas hospitalares exercem um papel na disseminação de IRAS, muitas vezes, como reservatórios secundários, sendo capaz de promover contaminação cruzada. ${ }^{(4)}$ Neste cenário, não menos importante, o uso de condicionadores de ar como prática de climatização ambiental artificial mantém o ar reciclado com partículas microbianas e aerossóis, que comprometem a qualidade do mesmo, constituindo-se como fator de risco para a doença infecciosa. ${ }^{(5)}$

As práticas de limpeza e desinfecção (L/D) de ambientes, superfícies e equipamentos fazem parte dos programas de controle de infecção, na tentativa de adequar o ambiente, minimizando o risco de doenças. ${ }^{(4,6,7)}$ Neste cenário, o uso de desinfetantes é uma prática padrão para o controle microbiano, incluindo a vaporização com formaldeído, ácido peracético ou clorexidina, hipoclorito de sódio e for- mulaçóes isoladas ou combinadas com peróxido de hidrogênio. ${ }^{(8)}$ Tais métodos têm desvantagens, como o alto custo, a prática laboral de preparo, além do potencial para inalação dos vapores tóxicos pelos profissionais que atuam próximos aos produtos. ${ }^{(9,10)}$

Nessa perspectiva, o ozônio é apresentado na forma triatômica do oxigênio $\left(\mathrm{O}_{3}\right)$ e vem sendo utilizado como elemento químico de controle de microrganismos em diversos segmentos da área $\mathrm{da}$ saúde, destacando-se no tratamento aos resíduos hospitalares, ${ }^{(11)}$ pré-tratamento da cavidade dentária, ${ }^{(12)}$ desinfecção de máquinas de hemodiálise, ${ }^{(13)}$ desinfecção de salas cirúrgicas, ${ }^{(14)}$ entre outros.

$\mathrm{Na}$ área de alimentos, o processo de sanitização vem sendo estruturado por equipamentos geradores de ozônio, resultando em ambiente adequado para os processos de maturação de queijos. ${ }^{(15-17)}$

Considerando a açáo antimicrobiana, o $\mathrm{O}_{3}$ atua na oxidação de glicopeptídeos, glicoproteínas e aminoácidos da parede celular, modificando a permeabilidade e ocasionando a lise celular. Ao penetrar no interior da célula, $\mathrm{o}_{3}$ recombina-se com elementos citoplasmáticos acarretando a oxidação de aminoácidos e ácidos nucléicos, consequentemente a clivagem e morte celular. Além disso, o $\mathrm{O}_{3}$ promove o colapso da atividade enzimática celular, atacando os grupos sulfidrila de enzimas, bem como modificando as bases púricas e pirimídicas dos ácidos nucleicos. ${ }^{(18-20)}$ 
Apesar de já ser utilizado em ambiente hospitalar há algum tempo, pouco se sabe sobre o potencial desse agente, principalmente em um contexto brasileiro de assistência, tendo em vista a escassez de estudo sobre o tema. Nessa perspectiva, esta pesquisa objetivou avaliar a ação antimicrobiano do gás $\mathrm{O}_{3}$ em superfícies e ar ambiente climatizado artificialmente.

\section{Métodos}

\section{Tipo de estudo}

Trata-se de uma pesquisa experimental/laboratorial e transversal realizada em dez salas internas de um laboratório de pesquisa em microbiologia clínica, que realiza exames bacteriológicos e micológicos como parte de projetos de pesquisas. Esse ambiente segue os critérios de biossegurança - Nível de Biossegurança 2 (NB2), apresentando condiçóes físico-químicas estáveis (umidade, temperatura e limpeza e desinfecção padrão). No entanto, se caracteriza como uma área crítica, com possibilidade de contaminação microbiana. As salas apresentam dados comuns quanto à área física, iluminação, temperatura, umidade e circulação de pessoas, portanto estáo sujeitas às mesmas condiçóes de risco microbiano. Fazem parte das bancadas: estufas, luminárias, banho maria, computadores e armários de madeira.

\section{Protocolo do estudo}

Dez salas de ambiente controlado, com área de $9 \mathrm{~m}^{2}$ foram submetidas à análise microbiológica antes e após uma hora de exposição do gás $\mathrm{O}_{3}$, gerado por dois equipamentos: geradores de $\mathrm{O}_{3}$ - GEO 20000/AR-TD (Mod.I) e GEO 20000/ AR (Mod.II), produzidos pela empresa OZON (Quadro 1). A produção do $\mathrm{O}_{3}$ ocorre por descarga eletroquímica, onde o equipamento é composto por dois eletrodos (alta e baixa tensão) que são submetidos a diferentes potenciais de ação, e a passagem de ar $\left(\mathrm{O}_{2}\right)$ entre os dois eletrodos produz mudança eletrostática, com geração de $\mathrm{O}_{3}$. Ressalta-se que o ambiente em que está sendo gerado o $\mathrm{O}_{3}$ esteja livre de pessoas. Os experi- mentos conduzidos pelos dois equipamentos I e II ocorreram em um intervalo de 6 meses.

Quadro 1. Modelos GEO 20000/AR-TD (Mod.I) e GE0 20000/ AR (Mod.II)

\begin{tabular}{|l|c|c|}
\hline Especificações técnicas & GE0 20000-AR/TD (Mod.I) & GE0 20000/AR (Mod.II) \\
\hline Vazão $\left(\mathrm{m}^{3} / \mathrm{h}\right) / \mathrm{ppm}$ 0zônio & $200 / 2,0 \mathrm{ppm}$ & $100 / 2,1 \mathrm{ppm}$ \\
\hline Umidade relativa máxima (\%) & 75 & 75 \\
\hline Temperatura de trabalho $\left({ }^{\circ} \mathrm{C}\right)$ & $6-35$ & $5-40$ \\
\hline Potência nominal $(\mathrm{W})$ & 135 & 127 \\
\hline Tensão de alimentação $(\mathrm{V})$ & 127 & 110 \\
\hline Peso $(\mathrm{kg})$ & 5,40 & 4,9 \\
\hline Área máxima de trabalho $\left(\mathrm{m}^{2}\right)$ & 300 & 300 \\
\hline Dimensões $(\mathrm{cm})$ & $18 \times 30 \times 47,5$ & $18 \times 30 \times 37$ \\
\hline
\end{tabular}

M $3 / \mathrm{H}$ - Metro cúbico por hora; \% - Porcentagem; ${ }^{\circ} \mathrm{C}$ - Grau Celsius; W - Watt; V - Volt; KG - Kilograma; $\mathrm{M}^{2}$ - Metro quadrado; CM - Centímetro; PPM - Partes por milhão

Para a investigação microbiológica das superfícies da parede, chão e bancada, a coleta foi conduzida por um swab pré-umedecido em água destilada estéril, sendo posto em contato sobre a área específica de um quadrante de $30 X 30 \mathrm{~cm}^{2}$. Seguiu-se com a inoculação imediata do mesmo na superfície de meio de cultura contendo BHI e incubação a $35^{\circ} \mathrm{C}$ por 24 horas. $\mathrm{Na}$ etapa subsequente do experimento, o equipamento gerador de $\mathrm{O}_{3}$ localizado no chão da parte central das salas, foi ligado por uma hora, e a área de investigação mantida fechada e lacradas durante todo o procedimento de sanitização, sem qualquer interferência. Ao término deste período, novas coletas foram realizadas, utilizando-se um outro swab, agora, submetido ao contato da superfície diametralmente oposta do quadrante, seguindo-se os procedimentos de análise como da primeira etapa. A figura 1 ilustra as áreas investigadas, bem como a disposição do aparelho gerador de $\mathrm{O}_{3}$.

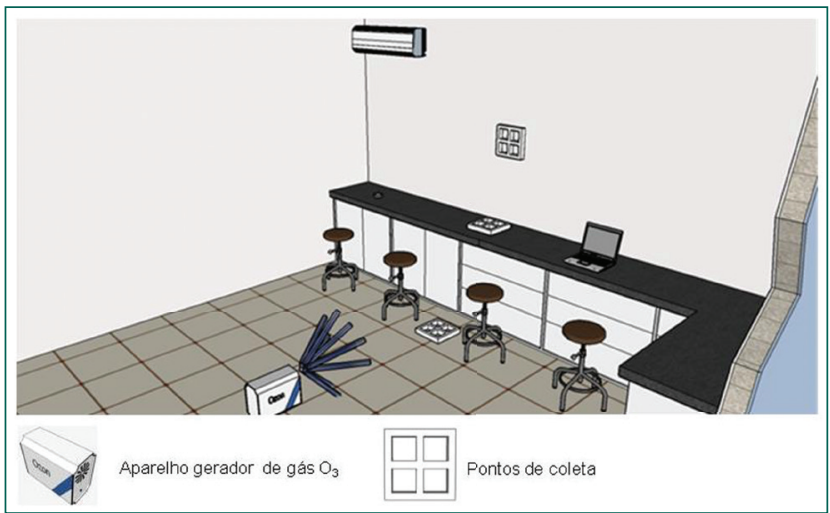

Figura 1. Figura ilustrativa da disposição do ozonizador e pontos coletados 
As amostras de ar ambiente foram coletadas por meio da técnica de sedimentação simples, antes e após uma hora de exposição do gás $\mathrm{O}_{3}$, e constituiu um parâmetro de investigaçáo, com exposição de placas de Petri, contendo BHI, mantidas abertas por uma hora e incubação das mesmas a $35^{\circ} \mathrm{C}$, por 24 horas (Figura 2). Registros de temperatura e umidade das salas foram monitorados.

A ação antimicrobiana foi elaborada por contagem das Unidades Formadoras de Colônias (UFC) na superfície da placa de Petri, do inóculo oriundo das superfícies de chão, bancada, parede e ar do ambiente, antes e após o tratamento com $\mathrm{O}_{3}$.

A recomendação clássica e consensual dos métodos seguros para desinfecção das superfícies consiste na limpeza prévia do local, seguida de desinfecção com um agente microbicida. ${ }^{(21)}$ No atual estudo, as superfícies foram analisadas sem nenhum processo

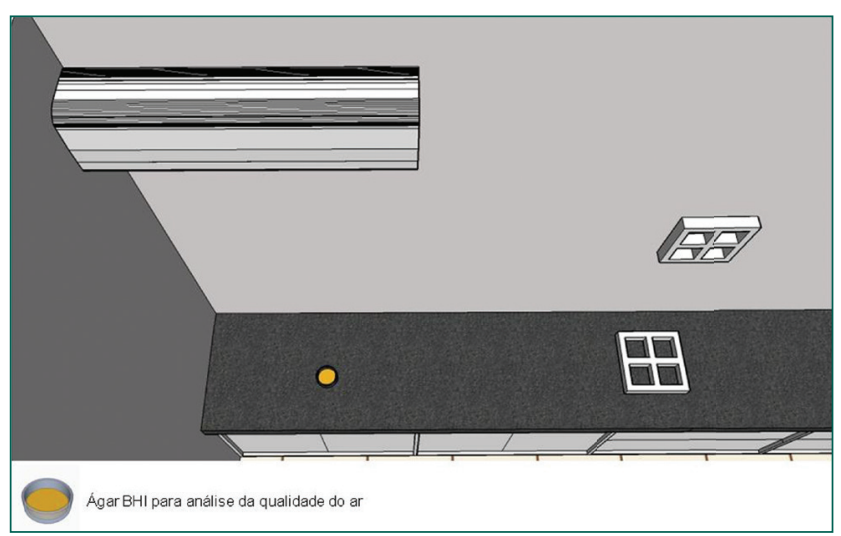

Figura 2. Figura ilustrativa da disposição da placa de Petri para análise do ar de limpeza prévia, pois os objetivos previam a análise da redução microbiana original.

\section{Análise dos dados}

Os dados coletados foram consolidados no software SPSS (20.0), submetidos á análise estatística, por meio do teste $t$ de student pareado para comparar as duas amostras, (antes e depois) e verificar se existe diferença significativa de uma variável entre os dois grupos de interesse. O teste de Wilcoxon foi utilizado para verificar de modo geral a eficiência dos aparelhos ozonizadores, que consiste em um método náo-paramétrico para comparação de duas amostras.

\section{Resultados}

A atividade antimicrobiana do gás ozônio foi efetiva para todas as áreas estudadas, com registros de redução do número de UFC, frente aos dois equipamentos (Tabelas 1 e 2).

Considerando-se a atividade do ozônio gerado pelo equipamento I, no chão de todas as salas, houve redução da carga microbiana (UFC) e negativação da contagem para sala 1. Este evento também foi observado para as bancadas, com a exceção da sala 4, que manteve a mesma contagem de colônias, antes e após a aplicação do ozônio. Considerandose as paredes, $50 \%$ apresentaram redução da contaminação microbiana. Considerando o ar ambiental como objeto de análise, notou-se uma redução da

Tabela 1. Apresentação numérica da UFC e percentual obtidos antes (A) e após (D) a exposição do ozônio (APARELHO I) em dez salas

\begin{tabular}{|c|c|c|c|c|c|c|c|c|c|c|}
\hline Local & Sala 1 & Sala 2 & Sala 3 & Sala 4 & Sala 5 & Sala 6 & Sala 7 & Sala 8 & Sala 9 & Sala 10 \\
\hline \multicolumn{11}{|l|}{ Chão } \\
\hline A (UFC) & 1 & 7 & 2 & 19 & 9 & 17 & 110 & 10 & 11 & 30 \\
\hline D (UFC) & 0 & 5 & 1 & 4 & 6 & 10 & 105 & 7 & 5 & 25 \\
\hline$\%$ & 100 & 29 & 50 & 79 & 33 & 41 & 5 & 30 & 55 & 17 \\
\hline \multicolumn{11}{|l|}{ Bancada } \\
\hline A (UFC) & 10 & 7 & 10 & 2 & 32 & 30 & 18 & 3 & 12 & 44 \\
\hline $\mathrm{D}$ (UFC) & 7 & 5 & 5 & 2 & 31 & 21 & 2 & 2 & 6 & 10 \\
\hline$\%$ & 30 & 29 & 50 & 0 & 3 & 30 & 89 & 33 & 50 & 77 \\
\hline \multicolumn{11}{|l|}{ Parede } \\
\hline A (UFC) & 1 & 0 & 1 & 1 & 1 & 14 & 0 & 3 & 2 & 1 \\
\hline $\mathrm{D}$ (UFC) & 0 & 0 & 1 & 1 & 1 & 8 & 0 & 0 & 0 & 0 \\
\hline$\%$ & 100 & 0 & 0 & 0 & 0 & 43 & 0 & 100 & 100 & 100 \\
\hline \multicolumn{11}{|l|}{$\mathrm{Ar}$} \\
\hline A (UFC) & 0 & 1 & 1 & 3 & 1 & 11 & 0 & 2 & 0 & 6 \\
\hline $\mathrm{D}$ (UFC) & 0 & 0 & 0 & 1 & 0 & 6 & 0 & 0 & 0 & 3 \\
\hline$\%$ & 0 & 100 & 100 & 67 & 100 & 45 & 0 & 100 & 0 & 50 \\
\hline
\end{tabular}

A - Antes; D - Após; \% - Percentagem de redução microbiana 
Tabela 2. Apresentação numérica da UFC e percentual obtidos antes (A) e após (D) a exposição do ozônio (APARELHO II) em dez salas

\begin{tabular}{|c|c|c|c|c|c|c|c|c|c|c|}
\hline Local & Sala 1 & Sala 2 & Sala 3 & Sala 4 & Sala 5 & Sala 6 & Sala 7 & Sala 8 & Sala 9 & Sala 10 \\
\hline \multicolumn{11}{|l|}{ Chão } \\
\hline A (UFC) & 89 & 479 & 309 & 94 & 193 & 182 & 782 & 186 & 55 & 114 \\
\hline D (UFC) & 22 & 39 & 68 & 74 & 162 & 69 & 167 & 131 & 53 & 74 \\
\hline$\%$ & 75 & 92 & 78 & 22 & 16 & 62 & 79 & 30 & 4 & 35 \\
\hline \multicolumn{11}{|l|}{ Bancada } \\
\hline A (UFC) & 23 & 36 & 0 & 281 & 5 & 15 & 9 & 73 & 26 & 54 \\
\hline D (UFC) & 16 & 19 & 0 & 55 & 4 & 2 & 5 & 4 & 7 & 41 \\
\hline$\%$ & 30 & 47 & 0 & 80 & 20 & 87 & 45 & 95 & 73 & 24 \\
\hline \multicolumn{11}{|l|}{ Parede } \\
\hline A (UFC) & 3 & 0 & 0 & 1 & 0 & 4 & 1 & 3 & 1 & 1 \\
\hline D (UFC) & 0 & 0 & 0 & 1 & 0 & 3 & 0 & 1 & 1 & 0 \\
\hline$\%$ & 100 & 0 & 0 & 0 & 0 & 25 & 100 & 67 & 0 & 100 \\
\hline \multicolumn{11}{|l|}{$\mathrm{Ar}$} \\
\hline A (UFC) & 0 & 1 & 1 & 0 & 1 & 4 & 0 & 0 & 2 & 1 \\
\hline D (UFC) & 0 & 0 & 0 & 0 & 0 & 0 & 0 & 0 & 0 & 0 \\
\hline$\%$ & 0 & 100 & 100 & 0 & 100 & 100 & 0 & 0 & 100 & 100 \\
\hline
\end{tabular}

A - Antes; D - Após; \% - Percentagem de redução microbiana

contaminação em sete salas, sendo que nas demais não foram detectados microrganismos nem antes (A) e após (D) a exposição do $\mathrm{O}_{3}$.

Os resultados obtidos da atividade antimicrobiana do gás ozônio, frente ao equipamento II estão apresentados na tabela 2. Novamente, ficou evidente a atividade antimicrobiana, uma vez que houve redução da UFC para todas as variáveis estudadas, como ar e superfícies, antes e após a exposição do gás $\mathrm{O}_{3}$. Foi observada apenas em duas salas (4 e 9) a manutenção do número de UFC para os dois tempos de investigação.

Independentemente dos equipamentos, o controle microbiano foi maior para as áreas de chão e bancada. Além disso, considerando todas as áreas investigadas, o Mod.I e o Mod.II apresentaram diferenças estatísticas significativas $(\mathrm{p}<0,05)$. Quando avaliados separadamente, em relação a cada uma das superfícies e o ar ambiental, os resultados não foram significantes, com exceção da parede $(p=0,0639)$ e bancada $(\mathrm{p}=0,1267)$, respectivamente.

Ressalta-se que os equipamentos I e II apresentam vazão de gás ozonizado e concentração distintos, isto é, de 200 e $100 \mathrm{~m}^{3} / \mathrm{h}$ - 2,0 e 2,1 ppm de gás ozônio, respectivamente. Os registros de temperatura e a umidade das salas mostraram valores médios de $21^{\circ} \mathrm{C}$ e $58 \%$ para os dois momentos de investigação.

\section{Discussão}

Esta pesquisa possui limitaçóes associadas ao desenho de estudo (experimental-laboratorial e trans- versal). A condição ambiental das salas laboratoriais foi considerada como parâmetro de análise e inferência para o ambiente hospitalar. No entanto, isto não descaracteriza a importância da pesquisa como protótipo para a avaliação da ação microbiológica, em dois tempos de investigação, antes a após a exposição do ozônio. Neste sentido, os pesquisadores pretenderam mimetizar a realidade de ambientes, quanto à ocorrência de microrganismos presentes em superfícies e no ar, introduzir o processo de sanitização, para depois desenvolver protocolos de higienização ambiental.

A aplicabilidade prática do gás $\mathrm{O}_{3}$ em ambiente hospitalar pode melhorar a condição microbiológica, prevenindo e podendo contribuir para a redução das taxas de IRAS. Além disso, a característica portátil do equipamento torna o processo de sanitização móvel e factível para monitoramento de áreas hospitalares específicas.

Já é conhecido que o $\mathrm{O}_{3}$ faz parte da rotina de desinfecção e sanitização de outros ambientes, ${ }^{(22)}$ com controles para bactérias e fungos. ${ }^{(15,17)}$ No entanto, este estudo vem expandir o que já se sabe sobre o gás, uma vez que a negativação do crescimento microbiano, ou redução da contagem de UFC em placas após a exposição do gás $\mathrm{O}_{3}$ para qualquer superfície analisada, em comparação ao grupo controle, comprova a eficácia do composto químico nos processos de controle microbiano. Evento semelhante foi narrado na descontaminação de sala cirúrgica de um Hospital Veterinário. ${ }^{(14)}$ Nos dois estudos, fica evidente o potencial do gás $\mathrm{O}_{3}$ no processo de desinfecção de ambiente, uma vez que 
a diminuição na contagem de aeróbios mesófilos, bolores e leveduras ocorreu com frequência.

Considerando-se o processo de eliminação microbiana pelo gás $\mathrm{O}_{3}$, é conhecido que a destruição celular se dá por oxidação de elementos estruturais, sem especificidade a alvos presentes na célula bacteriana ou fúngica. ${ }^{(18)}$ Neste sentido, organismos multirresistentes podem ser eliminados, com ampla vantagem, se comparados aos métodos de desinfecção mecânica com desinfetantes líquidos de superfícies ambientais em Estabelecimentos de Assistência à Saúde (EAS), incluindo o ambiente hospitalar, onde é comum a utilização de outros compostos químicos na forma líquida.

São fundamentais nas pesquisas epidemiológicas, amostras biológicas que indicam o ambiente ou superfícies como prováveis reservatórios na transmissão de IRAS. ${ }^{(23,24)}$ Nos hospitais, a limpeza terminal é feita abrangendo áreas e superfícies próximas ou em contato com o paciente, após a saída do mesmo, seja por óbito, transferência ou término de isolamento, ${ }^{(24-27)}$ e, apesar dos esforços, nem sempre o resultado dos processos de L/D é satisfatório. ${ }^{(28,29)} \mathrm{O}$ uso do gás $\mathrm{O}_{3}$ na pesquisa traz comprovação científica sobre o potencial controle microbiano, desta forma, o $\mathrm{O}_{3}$ mostra-se um composto capaz de ser utilizado como procedimento de sanitização de ambientes constituintes da área da saúde.

Nesta pesquisa, foram observadas diferenças entre dois equipamentos geradores de gás $\mathrm{O}_{3}$, em relação ao potencial antimicrobiano sobre as mesmas condiçóes na sanitização de ambientes, com destaque à vazão e potência nominal dos aparelhos. Os resultados mostraram diferenças significativas para alguns parâmetros, porém, de modo geral, de um modelo para outro, o potencial sanitizante foi próximo. Protocolos inovadores poderão ser criados com o objetivo de melhorar o padrão antimicrobiano aqui detectado.

Os valores de UFC de uma sala para outra apresentaram diferenças. Isso mostra que um ambiente nem sempre apresenta as mesmas condiçôes microbiológicas, evento esperado, considerando-se o ambiente hospitalar. Com a delimitação de áreas investigadas, antes e após o tratamento com o gás $\mathrm{O}_{3}$, tem-se apenas uma amostragem de área da superfície, o que não garante que em toda extensão, os resultados seriam os mesmos. Mais uma vez, a prática de sanitização pelo ozônio, gerado por equipamento portátil, certamente viabiliza a implantação de novas medidas de controle microbiano no ambiente hospitalar.

As superfícies do chão e bancadas apresentaram maior contagem no número de UFC, e, ao mesmo tempo, corresponderam às áreas de maior inibição microbiana pelo ozônio. As partículas microbianas são densas em relação ao ar, fato que normalmente contribui para a permanência de patógenos potenciais no chão de ambiente nosocomial. ${ }^{(30)}$ Neste sentido, o equipamento portátil pode ser levado próximo às áreas de alta contaminação ambiental e reduzir a carga microbiana.

Segundo a literatura, o efeito antimicrobiano do $\mathrm{O}_{3}$ depende de alguns fatores como o tempo de exposição, concentração, temperatura e umidade. ${ }^{(31)}$ No entanto, no atual estudo, estes critérios foram avaliados e mantidos em igualdade de condiçôes experimentais minimizando possíveis vieses. Nesse sentido, faz-se necessário outros estudos que considerem outros parâmetros de temperatura, da umidade relativa, concentração e o tempo de exposição.

$\mathrm{O} \mathrm{O}_{3}$, quando inalado em altas concentraçóes, pode ser tóxico, apresentando riscos à saúde respiratória. ${ }^{(32)}$ Os dois equipamentos testados geram pequena quantidade de ozônio (2,0-2,1 ppm), e durante a sua utilização, não devem permanecer pessoas no ambiente.

Deve-se considerar a pequena importância dada em relação à qualificaçáo do grupo do Serviço de Limpeza e Desinfecção de Superfícies em Serviços de Saúde, o qual possui papel essencial na redução das IRAS. Desta forma, é fundamental que as práticas de L/D de ambientes, equipamentos e superfícies façam parte das Comissôes de Controle de Infecção Hospitalar, junto com a enfermagem e serviços de limpeza, desenvolvendo atividades relacionadas a protocolos de higiene ambiental, supervisão e treinamento das equipes. ${ }^{(33,34)}$ Outro ponto importante de se destacar na utilização de tecnologias que não utilizam a ação mecânica para realizarem a desinfecção de ambientes e superfícies é o fato que áreas adjacentes não são garantidas de serem desinfetadas, assim, não substituem a ação mecânica de L/D. ${ }^{(35)}$ 
Por fim, ressalta-se que a busca por novos produtos ou métodos e práticas hospitalares para desinfecção de superfícies e redução da microbiota de ar artificialmente climatizado vem se intensificando ao longo do tempo, sendo o gás $\mathrm{O}_{3}$ um composto promissor. Ainda não há muitos estudos na literatura abordando esse objeto de pesquisa, e aqueles que o fazem apresentam condiçôes experimentais bem variadas, o que sugere a necessidade de criação de protocolos bem elaborados, para fins de controle microbiano.

\section{Conclusão}

Nossos achados evidenciam o potencial antimicrobiano do gás $\mathrm{O}_{3}$ produzido pelos dois equipamentos e os critérios descritos obedecidos garantiram uma ação antimicrobiana. A ozonização do ambiente se constitui um procedimento prático de sanitização de superfícies e ar climatizado artificialmente. Depreende-se que essa tecnologia seja factível para utilização em diversos segmentos onde se busca a redução da densidade microbiana. Este recurso poderá compor os protocolos de sanitização de ambientes e superfícies hospitalares, valorizada a rapidez e facilidade de execução, garantindo o controle de desenvolvimento microbiano, condição fundamental para a manutenção da qualidade ambiental microbiologicamente segura.

\section{Agradecimentos}

O presente trabalho foi realizado com apoio da Universidade Federal de Mato Grosso do Sul UFMS/MEC-Brasil" e com apoio da Coordenação de Aperfeiçoamento de Pessoal de Nível Superior - Brasil (Capes) - Código de Financiamento 001".

\section{Colaborações}

Caetano MH, Siqueira JPZ, Andrade D, Sousa AFL, Rigotti MA, Diniz MO, Almeida WA, Ferreira AM, Almeida MTG declaram que contribuíram com a concepção do estudo, análise e interpretação dos dados, redação do artigo e revisão crítica do conteúdo intelectual. Todos os autores aprovaram a versão final a ser publicada.

\section{Referências}

1. Giroti AL, Ferreira AM, Rigotti MA, Sousa ÁF, Frota OP, Andrade D. Hospital infection control programs: assessment of process and structure indicators. Rev Esc Enferm USP. 2018 ;52:e03364.

2. Santos-Junior AG, Ferreira AM, Frota OP, Rigotti MA, Barcelos LD, Lopes de Sousa AF, et al. Effectiveness of surface cleaning and disinfection in a Brazilian healthcare facility. Open Nurs J. 2018;12:36-44.

3. Padoveze MC, Juskevicius LF, Santos TR, Nichiata LI, Ciosak SI, Bertolozzi MR. The concept of vulnerability applied to Healthcareassociated Infections. Rev Bras Enferm. 2019;72(1):299-303.

4. Furlan MC, Ferreira AM, da Silva Barcelos L, Rigotti MA, de Sousa AF, Dos Santos Junior AG, et al. Evaluation of disinfection of surfaces at an outpatient unit before and after an intervention program. BMC Infect Dis. 2019;19(1):355.

5. Silva D, Nazaré D, Muniz J, Câmara C. [Hospital-acquired infections associated with poor air quality in air-conditioned environments]. J Epidemiol Infect Control. 2013;3(4):153-7. Portuguese.

6. Frota OP, Ferreira AM, Guerra OG, Rigotti MA, Andrade D, Borges NM, et al. Efficiency of cleaning and disinfection of surfaces: correlation between assessment methods. Rev Bras Enferm. 2017;70(6):117683.

7. Han JH, Sullivan N, Leas BF, Pegues DA, Kaczmarek JL, Umscheid CA. Cleaning hospital room surfaces to prevent health care-associated infections. Ann Intern Med. 2015;163(8):598-607.

8. Sato Y, Ishihara M, Nakamura S, Fukuda K, Kuwabara M, Takayama $\mathrm{T}$, et al. Comparison of various disinfectants on bactericidal activity under organic matter contaminated environments. Biocontrol Sci. 2019;24(2):103-8.

9. Chughtai AA, Stelzer-Braid S, Rawlinson W, Pontivivo G, Wang Q, Pan $Y$, et al. Contamination by respiratory viruses on outer surface of medical masks used by hospital healthcare workers. BMC Infect Dis. 2019;19(1):491.

10. West AM, Teska PJ, Lineback CB, Oliver HF. Strain, disinfectant, concentration, and contact time quantitatively impact disinfectant efficacy. Antimicrob Resist Infect Control. 2018;7(1):49.

11. Hansen KM, Spiliotopoulou A, Chhetri RK, Escolà Casas M, Bester K, Andersen HR. Ozonation for source treatment of pharmaceuticals in hospital wastewater-ozone lifetime and required ozone dose. Chem Eng J. 2016;290:507-14.

12. Sancakli HS, Siso SH, Yildiz SO, Gökçe YB. Antibacterial effect of surface pretreatment techniques against Streptococcus Mutans. Niger J Clin Pract. 201821(2):170-5.

13. Canada ML, Abelan US, Zangaro RA, Kozusny-Andreani DI, Yamazaki RF. Effectiveness of ozonated water in the reprocessing of blood dialyzers. Rev Bras Eng Bioméd. 2014;30(3):215-9.

14. Garcia CA, Naves JH, Neves SM, Stanziola L, Vieira IS. Ozone gas in the decontamination of surgical environments]. Vet Not. 2008;14(2):3740. Portuguese. 
15. Pinto AT, Schmidt V, Raimundo SA, Raihmer F. Uso de ozônio no controle de fungos em sala de maturação de queijos. Acta Sci Vet. 2007;35(3):333-7.

16. Lanita CS, Silva SB. [Use of ozone in industrial cold rooms to control yeasts and moulds during parmesan cheese ripening]. Braz J Food Technol. 2008;11(3):182-9. Portuguese.

17. Cavalcante DA, Leite Júnior BR, Tribst AA, Cristianini M. Uso de ozônio gasoso na sanitização de câmaras frigoríficas. Rev Inst Laticínios Cândido Tostes. 2014;69(2):121-8.

18. Tormin SC, Navarini A, Almeida J0, Travassos LH, Negri MV, Silva RA. [Analysis of bactericidal effect of ozone on multi-resistant bacteria] [Portuguese]. Arq Med Hosp Fac Cienc Med Santa Casa São Paulo. 2016;61:138-41.

19. Hunt NK, Mariñas BJ. Inactivation of Escherichia coli with ozone: chemical and inactivation kinetics. Water Res. 1999;33(11):2633-41.

20. Martins CC, Kozusny-Andreani DI, Mendes EC. [Ozone in the control of microorganisms in health care waste]. खRev Baiana Enferm. 2015;29(4):318-27. Portuguese .

21. Agência Nacional de Vigilância Sanitária (ANVISA). Segurança do paciente em serviços de saúde: limpeza e desinfecção de superfícies. Brasília (DF): ANVISA [Internet]. 2012 [citado 2020 Jan 21]. Disponível em: https://www20.anvisa.gov.br/segurancadopaciente/index.php/ publicacoes/item/seguranca-do-paciente-em-servicos-de-saudelimpeza-e-desinfeccao-de-superficies

22. Coelho CC, Freitas-Silva O, Campos RS, Bezerra VS, Cabral LM. [Ozonation as post-harvest technology in conservation of fruits and vegetables: A review]. Rev Bras Eng Agríc Ambiental. 2015;19(4):36975. Portuguese

23. Otter JA, Yezli S, French GL. The role played by contaminated surfaces in the transmission of nosocomial pathogens. Infect Control Hosp Epidemiol. 2011;32(7):687-99.

24. Rutala WA, Weber DJ. Are room decontamination units needed to prevent transmission of environmental pathogens? Infect Control Hosp Epidemiol. 2011;32(8):743-7.

25. Arroyo MG, Ferreira AM, Frota OP, Rigotti MA, de Andrade D, Brizzotti $\mathrm{NS}$, et al. Effectiveness of ATP bioluminescence assay for presumptive identification of microorganisms in hospital water sources. BMC Infect Dis. 2017;17(1):458.

26. Anderson DJ, Moehring RW, Weber DJ, Lewis SS, Chen LF, Schwab JC, et al.; CDC Prevention Epicenters Program. Effectiveness of targeted enhanced terminal room disinfection on hospital-wide acquisition and infection with multidrug-resistant organisms and Clostridium difficile: a secondary analysis of a multicentre cluster randomised controlled trial with crossover design (BETR Disinfection). Lancet Infect Dis. 2018 Aug;18(8):845-53.

27. Mitchell BG, Hall L, White N, Barnett AG, Halton K, Paterson DL, et al. An environmental cleaning bundle and health-care-associated infections in hospitals (REACH): a multicentre, randomised trial. Lancet Infect Dis. 2019;19(4):410-8.

28. Rutala WA, Weber DJ. Monitoring and improving the effectiveness of surface cleaning and disinfection. Am J Infect Control. 2016;44(5 Suppl):e69-76.

29. Doll M, Stevens M, Bearman G. Environmental cleaning and disinfection of patient areas. Int J Infect Dis. 2018;67:52-7.

30. Salimifard P, Rim D, Gomes C, Kremer P, Freihaut JD. Resuspension of biological particles from indoor surfaces: effects of humidity and air swirl. Sci Total Environ. 2017;583:241-7.

31. Kim JG, Yousef AE, Dave S. Application of ozone for enhancing the microbiological safety and quality of foods: a review. J Food Prot. 1999;62(9):1071-87.

32. Nuvolone D, Petri D, Voller F. The effects of ozone on human health. Environ Sci Pollut Res Int. 2018;25(9):8074-88.

33. Furlan MC, Ferreira AM, Rigotti MA, Guerra OG, Frota OP, Sousa AF, et al. Correlation among monitoring methods of surface cleaning and disinfection in outpatient facilities. Acta Paul Enferm. 2019;32(3):2829.

34. Paina T, Rodrigues JN, Felippe JC, Nogueira PC, Paiva SM. Conhecimento de auxiliares de higienização sobre limpeza e desinfecção relacionados à infecção hospitalar. Rev Enferm UFSM. 2015;5(1):121-30.

35. Weber DJ, Kanamori H, Rutala WA. 'No touch' technologies for environmental decontamination: focus on ultraviolet devices and hydrogen peroxide systems. Curr Opin Infect Dis. 2016;29(4):424-31. 